\title{
UMA PALAVRA VALE MAIS DO QUE UM PROTOCOLO? (IN)FORMALIDADE NA COMUNICAÇÃO INTERNA ORGANIZACIONAL
}

\author{
Vandrea Moraes Ferreira" \\ Irene Raguenet Troccoli**
}

RESUMO: Este estudo de caso, de abordagem quantitativa com viés qualitativo, investiga a estrutura do processo de comunicação organizacional entre as áreas de pesquisa e de comunicação da Unidade Embrapa Agrobiologia, do ponto de vista dos pesquisadores científicos. Dentre as conclusões, destaca-se a falta de conhecimento desses pesquisadores sobre os trâmites de um protocolo processual. A contribuição acadêmica do estudo reside na indicação de que o desenho formal de um processo comunicacional empresarial sofre interferências advindas das características intrínsecas dos agentes nele envolvidos, passando a incorporar procedimentos informais. São lançadas sugestões para lidar com esse fato, além de propostas para futuras pesquisas.

PALAVRAS-CHAVE: Comunicação Organizacional; Embrapa; Protocolo Comunicacional.

\section{IS A WORD MORE WORTHY THAN A PROTOCOL? (IN)FORMALITY IN ORGANIZATIONAL INTERNAL COMMUNICATION}

ABSTRACT: Current case study, foregrounded on a quantitative and qualitative approach, investigates the structure of an organizational communication process between the research and communication areas of the Embrapa Agrobiologia Unit from the perspective of scientific researchers. Lack of knowledge on the development of procedure protocol may be highlighted. The academic contribution of current studies involves the fact that formal design of an entrepreneurship communication process undergoes interferences derived from intrinsic characteristics of the agents involved and incorporates informal procedures. Suggestions and recommendations for future research work are forwarded.

KEY WORDS: Organizational Communication; Embrapa; Communication Protocol.

\footnotetext{
"M.Sc., Mestrado em Administração e Desenvolvimento Empresarial (MADE), Universidade Estácio de Sá, Rio de Janeiro (RJ), Brasil.

* D.Sc, Mestrado em Administração e Desenvolvimento Empresarial (MADE), Universidade Estácio de Sá, Rio de Janeiro (RJ), Brasil; E-mail: irene.troccoli@estacio.br
} 


\section{INTRODUÇÃO}

Criada em 1973, a Empresa Brasileira de Pesquisa Agropecuária (Embrapa) tem como missão "[...] viabilizar soluções de pesquisa, desenvolvimento e inovação para a sustentabilidade da agricultura, em benefício da sociedade" (EMBRAPA, 2002). Isso tem permitido ao Brasil se destacar no cenário agropecuário mundial por meio da adoção de tecnologias agropecuárias modernas, radicais e incrementais, baseadas na criação e na adaptação de máquinas, de espécies de plantas e de animais, e de sistemas de manejo. Esse destaque tem refletido na melhoria do rendimento físico e das lavouras durante a década de 2000 e no aumento da produção de grãos e de proteínas animais no mesmo período. Essa constatação leva à suposição de que estaria sendo bem sucedido o repasse das descobertas científicas da Embrapa para o mercado e para a sociedade, repasse esse que encontra seus fundamentos no processo de comunicação entre a empresa e seus stakebolders externos. Todavia, Duarte e Ribeiro (2006) informam que, em maio de 2005, a empresa procedeu à revisão de sua política de comunicação, dando início a uma série de ajustes nas linhas, nos instrumentos, nas atividades e na sua estrutura. O então chefe da Assessoria de Comunicação da Embrapa, Edilson Fragalle, assinalou: "Apesar de termos avançado nos últimos anos na nossa comunicação, e até sermos benchmarking para algumas empresas, principalmente da área pública, temos ainda muitas deficiências na comunicação interna" (DUARTE; RIBEIRO, 2006, p. 491).

A literatura confirma que a comunicação com o público-alvo externo não prescinde do funcionamento a contento da comunicação interna à organização (ROMAN, 2009; HALL, 1984; MATOS, 2009; SILVA; SILVA, 2010; BUENO, 2005). As empresas devem procurar um equilíbrio nas suas diversas formas de comunicação, entendendo que falar com os funcionários é tão importante quanto com os consumidores (DUARTE; RIBEIRO, 2006). Isso porque a comunicação é um sistema único, que passa por dentro e por fora da empresa, gerando percepções positivas e negativas nos diferentes públicos da organização (NASSAR, 2006). No caso da Embrapa esses elementos são reforçados por se tratar de uma organização que produz conhecimento eminentemente científico, que precisa ser repassado a terceiros - usuários e clientes externos - e cujo processo envolve, intrinsecamente, o desenvolvimento de vários tipos de ações de comunicação para diversos públicos. 
E, para que esse processo se desenvolva sem percalços, é fundamental que não haja ruídos na troca de informações entre a área de pesquisa, diretamente envolvida na geração das tecnologias, e os profissionais de comunicação e de transferência de tecnologia no que tange especificamente às ações destinadas à divulgação dos resultados aos diversos públicos.

O objetivo deste artigo - que, além dessa introdução, conta com referencial teórico, descrição do método, resultados da pesquisa de campo, discussão dos resultados do levantamento de dados, e conclusão - é investigar a eventual existência desses percalços no processo de comunicação organizacional entre as áreas de pesquisa científica e de comunicação da Unidade Embrapa Agrobiologia. Para tanto, é examinada a estruturação desse processo, assim como sua interpretação e compreensão por parte dos pesquisadores científicos. Uma das justificativas dessa investigação é que a importância da comunicação no Marketing moderno transcende as empresas desenvolverem um bom produto, acessível aos seus consumidores-alvo e com preço considerado atraente (KOTLER, 1998). Outra justificativa advém da importância da integração das ferramentas de comunicação e dos pontos de contato, atuando de forma sinérgica para que as organizações alcancem seus objetivos (GALINDO, 2009). Isso remete ao Plano Diretor da Embrapa (PDE), documento que, com base em estudos no cenário mundial, reúne diversas informações sobre ações estratégicas de pesquisa e de gestão da empresa, para execução em um período previamente estabelecido. Sua última edição data de 2008 e indica ações para até 2023. Dentre elas se destacam algumas qualificadas como estratégicas, tais como o aprimoramento dos fluxos, dos canais e dos espaços formais e informais de diálogo e de influência recíproca que existem entre a Embrapa e seus públicos de interesse (EMBRAPA, 2008).

\section{REFERENCIAL TEÓRICO}

\subsection{COMUNICAÇÃO INTERNA ORGANIZACIONAL}

A comunicação pode ser definida como "[...] entendimento interpessoal, participação intencional ou socialização de informações com ajuda de sinais, sistemas 
de signos, sobretudo através da linguagem" (COLAUTO et al., 2006, p. 5). O processo de comunicação envolve um emissor dirigindo-se a um receptor - o público - restrito e determinado, usando um código - linguagem - adequado ao receptor e facilmente decifrável por ele (KUNSCH, 2003). Transmitida de forma apropriada, a mensagem tem também um retorno apropriado, tornando-se eficiente, com o processo de comunicação envolvendo três pontos básicos: a fonte, a mensagem e o destino (ILUFI, 2000). Dessa forma, comunicar é exercer uma atividade social (SOUZA, 2006), na qual indivíduos que partilham de uma mesma cultura criam e trocam significados, respondendo à realidade que experimentam cotidianamente. Essas duas proposições que apresentam a comunicação como um processo ou como uma atividade social não são estanques, mas complementares, porque " $[\ldots]$ as mensagens trocadas só têm efeitos cognitivos porque lhes são atribuídos significados e esses significados dependem da cultura e do contexto em geral que rodeiam quem está a comunicar" (SOUZA, 2006, p. 22).

Já no que se refere especificamente à comunicação interna organizacional, alguns autores a denominam como comunicação corporativa, outros de comunicação empresarial, ou ainda, Endomarketing ou Marketing interno (CLEMEN, 2005). Tratase de "[...] um complexo de produção, seja de ideias, normas, pensamentos, valores" (PEREIRA; MIRANDA, 2007, p. 6), o que sugere "[...] uma reflexão no sentido de que é possível, dentro dos limites de cada um e de cada setor, desenvolver-se uma comunicação interna para que a empresa alcance seus objetivos com maior eficiência e eficácia" (PEREIRA; MIRANDA, 2007, p. 6-7). Ou seja, a comunicação interna é direcionada a todos os colaboradores de uma organização, e o seu objetivo é promover a integração dos funcionários, a troca de informações e o estímulo às experiências e ao diálogo (LUPETTI, 2007). Essa comunicação, por seu turno, pode adotar padrões tanto formais como informais. No último caso, é vista como geradora de aumento de produtividade na escala de relações humanas, pois que, em uníssono como as políticas administrativas de recursos humanos, serve à integração dos stakeboders aos objetivos organizacionais, conforme contribui na construção de um universo simbólico (GOMES; SANTOS; RODRIGUEZ, 2012).

Trata-se de posição alvissareira, tendo em vista que, na prática, a perspectiva predominante da comunicação organizacional ainda é a instrumental 
ou mecanicista. Nela, padrões e regras estabelecidos a priori devem ser obedecidos. Qualquer comunicação não diretamente relacionada ao desempenho das tarefas pode ser mal vista, já que poderá sempre ameaçar a integridade da informação (NOGUEIRA; TOMEI, 2013). E manifestações paralelas são ignoradas, como ocorre no caso da não comunicação - caso do silêncio, que é a ausência de palavras ou de ruídos, mas que nem por isso deixa de ser uma forma de comunicação (ROBBINS; JUDGE; SOBRAL, 2011). Assim, na construção de uma organização confiável, é fundamental que as formas conhecidas de comunicação permitam que os membros identifiquem quanto há de declarativo e normativo nas mensagens diretivas, quanto há de conteúdo técnico e quanto há de decisão política (ETKIN, 2007). Contudo, "Esses 'acordos' não eliminam a ambiguidade que deriva das diferentes lógicas em uma organização complexa, mas permitem pôr em claro as intenções e regras do jogo que se sustenta desde a direção" (SOUZA; AÑEZ, 2012, p. 168). Esses aspectos tangenciam a questão da manifestação do poder pelas vias comunicacionais, fenômeno contido, por exemplo, no modelo de comunicação organizacional baseado no controle estratégico da comunicação, que atribui, aos comunicadores, objetivos múltiplos em face de situações. Trata-se de abordagem que ignora a ideia dos significados compartilhados como a base ou a motivação para a comunicação, fundamentando-se na perspectiva de que a posição e o poder individuais adquirem significado através da comunicação (SCROFERNEKER, 2014).

\subsection{MANIFESTAÇÃO DO PODER PELAS VIAS COMUNICACIONAIS}

"Uma organização [...] é uma unidade coletiva de ação formada para perseguir fins específicos e é dirigida por um poder que estabelece a autoridade, determina o status e o papel de seus membros" (CARDOSO, 2006, p. 1125-1126). Ao mesmo tempo, não se pode mais aceitar que o processo de comunicação, "[...] mantendo-se com seus modelos homogeneizados, verticalizados e com ênfase na instrumentalidade da comunicação [...] seja a maneira mais pertinente para responder aos desafios da gestão estratégica das organizações [...]" (CARDOSO, 2006, p. 1126). Controlar a comunicação e dominar a informação são formas de exercer poder, conforme se dominam a comunicação entre os agentes e os caminhos 
percorridos pelas mensagens (SOARES, 2004). "O poder é uma característica sempre presente na vida organizacional" (MILLER; HICKSON; WILSON, 2004, p. 286), sendo que o poder legítimo é alocado para posições de autoridade dentro da hierarquia da organização. Ainda no que se refere ao poder nas organizações, " $[. .$. falar em organização significa falar em poder, pois esse é parte essencial da realidade organizacional e jamais deixará de sê-lo" (TERCIOTTI, 2008, p. 25). Toda organização que pretende ser eficaz necessita implantar algumas práticas disciplinares globais, vez que a resistência a controles formais se encontra nos processos enquadrados em ambientes hierárquicos e que obedeçam a práticas disciplinares. Isso porque os elos hierárquicos raramente seriam passivos, conforme o poder se manifesta por meio das práticas disciplinares e das lutas que se opõem ou resistem a tais práticas (CLEGG, 2007). Assim, o poder se torna uma forma de comunicação, e essa, por sua vez, também se constitui em uma fonte e em um instrumento de poder (TERCIOTTI, 2008). Por conseguinte, nas organizações, se a comunicação eficaz facilita as relações de poder, a ineficaz as tornam mais difíceis. Ao mesmo tempo, conforme se constitui em fonte de instrumento de poder, a comunicação passa a apresentar uma relação muito clara com a cultura organizacional, conforme os valores e os pressupostos dessa última são transmitidos e reforçados pela comunicação. Por isso mesmo, nos ambientes organizacionais emergem contradições no trabalho em decorrência das muitas barreiras que ali são erigidas a um livre fluxo de ideias e de opiniões (CURVELLO, 1997), tendo em vista que a comunicação empresarial tradicionalmente conduzida busca, de forma prioritária, controlar e dominar as situações e os empregados (AKTOUF, 1996).

É nesse campo, onde se misturam poder, comunicação e cultura, que o primeiro passa a interferir não só nas estruturas hierárquicas formais, mas também na linguagem das corporações. Nesse ponto, os atores organizacionais podem ser submetidos tanto ao diálogo quanto ao silenciamento, o que provocaria a interdição da fala nas organizações e alimentaria os canais informais (TERCIOTTI, 2008). A comunicação interna não deve ser utilizada para fazer com que os colaboradores aceitem as decisões de superiores, dos presidentes e dos diretores sem muitas contestações. Na verdade, deveria ocorrer o contrário: os departamentos de comunicação interna deveriam ouvir as decisões e as ideias dos presidentes, 
transmitindo-as de forma clara e objetiva para o restante dos funcionários, atuando de forma imparcial na transmissão das mensagens (NASCIMENTO, 2010).

\section{MÉTODO}

Para atingir o objetivo proposto, essa pesquisa foi realizada em três fases: $\left.1^{a}\right)$ Foram buscadas, junto ao supervisor da área de comunicação da empresa, informações atinentes apenas aos processos formalmente previstos na empresa, independente de serem executados ou não, e independente de serem, ou não, complementados e ou substituídos por processos informais; $2^{\mathrm{a}}$ ) Foi realizada pesquisa documental, utilizando documentos internos da Embrapa (manuais, publicações internas, relatórios e Intranet), para mapear o processo de comunicação organizacional entre as áreas de pesquisa e de comunicação da Unidade Embrapa Agrobiologia - essa última oficialmente conhecida como Núcleo de Comunicação Organizacional (NCO); e $3^{\mathrm{a}}$ ) Foi realizada pesquisa de campo junto a todos os 44 pesquisadores científicos dessa Unidade para avaliar-lhes a interpretação desse processo, por meio de questionário autoadministrado aplicado remotamente em fins de 2012 e início de 2013, dos quais 33 foram tratáveis, com seis questões fechadas voltadas para a avaliação do perfil do pesquisado, e 13 questões (seis fechadas e sete questões abertas) referentes à sua percepção quanto a aspectos da comunicação interna. Portanto, quanto aos meios tratou-se de pesquisa bibliográfico-documental, de campo e survey. Também se tratou de estudo de caso, cuja unidade de análise foi a Embrapa Agrobiologia, com as unidades de observação tendo sido os pesquisadores científicos nela alocados (GONÇALVES; MEIRELLES, 2004), e com os dados obtidos na pesquisa primária tendo sido contrapostos às informações documentais da Embrapa atinentes à sua política comunicacional interna (YIN, 2005).

A abordagem foi quantitativa com uma vertente qualitativa, já que o instrumento de pesquisa foi desenhado para levantar tanto indicadores numéricos como evidências qualitativas. As informações sobre o perfil dos pesquisados foram tabuladas e tratadas pela estatística descritiva. Os aspectos da comunicação interna no caso das perguntas fechadas foram analisados pelo mapeamento das respostas e em 
seu tratamento por meio da estatística descritiva; no caso das abertas, foi analisado o conteúdo das respostas com grade aberta (BARDIN, 1977; VERGARA, 2010). O modelo utilizado no mapeamento do processo de comunicação organizacional foi o de Lasswell (1935), conforme disposto na Figura 1.

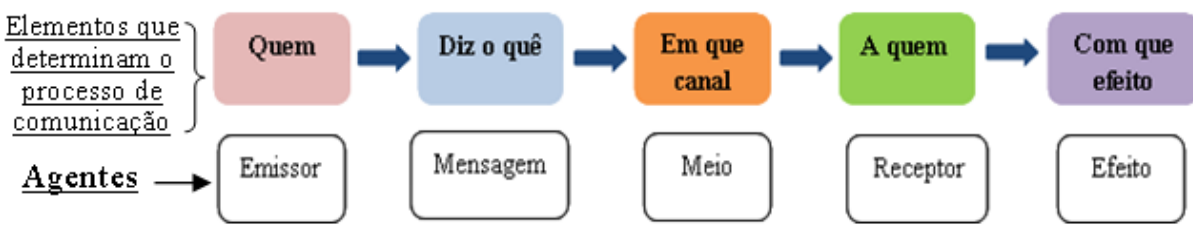

Figura 1. Representação do Paradigma de Comunicação de Lasswell (1935)

Fonte: Elaboração própria, adaptado de Tibério (2010)

\section{RESULTADOS DA PESQUISA DE CAMPO}

Na Fase 1, o mapeamento dos processos formalmente previstos na empresa permitiu constatar, de forma simplificada: 1) quais os atuais agentes responsáveis pela geração das informações e pelo seu repasse; e 2) quais as atuais formas e ordenações dos fluxos das informações entre todas as áreas indicadas, incluindo a interação entre a área de pesquisa (cujo papel é a geração de conhecimento e de tecnologias) e a área de comunicação da empresa, incumbida da divulgação dessas mesmas tecnologias para a sociedade (ver Figura 2).

$\mathrm{NaFase} 2$, a pesquisa documental mapeou os canais formais de comunicação existentes na estrutura da empresa (memorandos, sistemas, e-mails ${ }^{1}$, reuniões, relatórios) que ligam os players indicados na Figura 2. Foi identificado o IDEARE, sistema que permite a administração da carteira de projetos, e que foi concebido para acompanhar as mudanças da empresa, permitindo ajustes quando necessários, além de oferecer uma integração com outros sistemas corporativos internos. A análise documental também indicou que há diversos sistemas na Embrapa Agrobiologia, inclusive um sistema interno informatizado, disponível na Intranet da Unidade, chamado de Agenda de Eventos, que é o protocolo de comunicação entre a área de comunicação da Unidade e todas as demais, permitindo 1) o agendamento de

\footnotetext{
${ }^{1}$ Para Melo (2009), Mattos (2009) e Araújo e Freire (1996), o correio eletrônico é um canal formal.
} 
eventos por qualquer funcionário da Unidade, incluindo bolsistas $22 ; 2$ ) a marcação de espaços para a realização de atividades como cursos, reuniões e visitas; e 3) que qualquer setor, incluindo o setor de transferência de tecnologia, solicite o apoio da área de comunicação para confecção e distribuição de materiais de divulgação, como cartazes e folders, necessários aos eventos do setor.

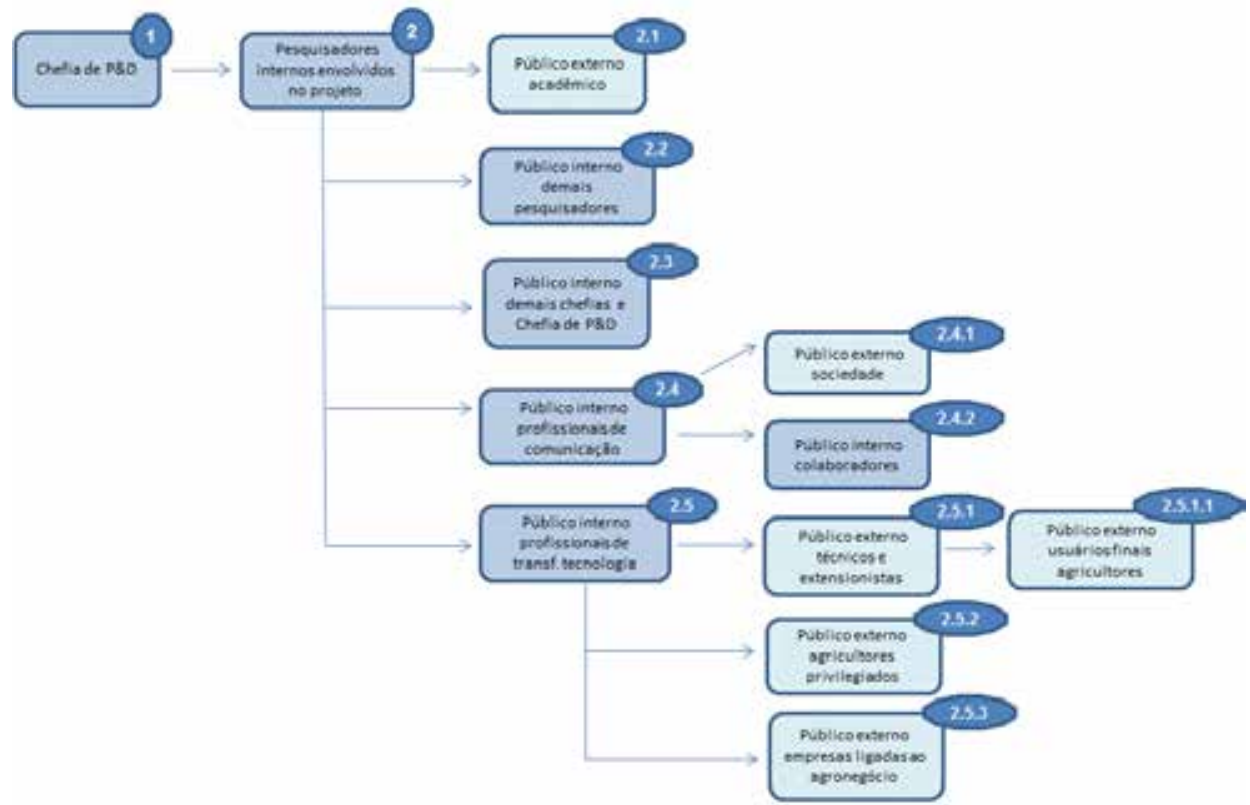

Nota: A cor escura indica os agentes relacionados ao público interno e a cor clara indica os agentes relacionados ao público externo

Figura 2. Unidade Embrapa Agrobiologia - Agentes atuantes na geração e na divulgação de conhecimentos, e indicação dos fluxos de disseminação desses conhecimentos na ordem das etapas em que ocorrem

Fonte: Elaboração própria

O Quadro 1 traz a organização das informações da Fase 2 à luz do paradigma de Lasswell (1935): a localização específica dos agentes emissores da

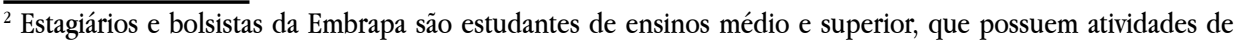
apoio à pesquisa e de iniciação científica, assim como ao mestrado e ao doutorado em projetos de pesquisa da Unidade.
} 
comunicação e do(s) respectivo(s) agente(s) recebedor(es) e veículos formais de comunicação utilizados.

Quadro 1. Embrapa Agrobiologia - Agentes emissores e recebedores da comunicação gerada, e veículos formais de comunicação utilizados.

\begin{tabular}{|c|c|c|}
\hline $\begin{array}{l}\text { Agente emissor } \\
\text { da comunicação }\end{array}$ & $\begin{array}{l}\text { Agente recebedor da } \\
\text { comunicação }\end{array}$ & Veículos formais de comunicação utilizados \\
\hline Chefia de P\&D & Pesquisadores & $\begin{array}{l}\text { E-mails, reuniões de pesquisa, informativo } \\
\text { interno. }\end{array}$ \\
\hline \multirow[b]{2}{*}{$\begin{array}{l}\text { Profissionais de } \\
\text { Comunicação }\end{array}$} & Sociedade & \multirow{2}{*}{$\begin{array}{l}\text { Matérias jornalísticas em veículos de } \\
\text { comunicação típicos de Endomarketing, matérias } \\
\text { jornalísticas em veículos de comunicação, } \\
\text { convites para participação em eventos } \\
\text { institucionais. }\end{array}$} \\
\hline & Colaboradores & \\
\hline \multirow[b]{2}{*}{$\begin{array}{l}\text { Profissionais de } \\
\text { Transferência de } \\
\text { Tecnologia }\end{array}$} & $\begin{array}{l}\text { Técnicos e } \\
\text { extensionistas }\end{array}$ & $\begin{array}{l}\text { Dias de Campo, palestras, cursos, participação } \\
\text { em feiras agropecuárias e em eventos técnicos, } \\
\text { publicações da Embrapa. }\end{array}$ \\
\hline & $\begin{array}{l}\text { a) Usuários finais } \\
\text { agricultores; } \\
\text { b) Agricultores } \\
\text { privilegiados; } \\
\text { c) Empresas ligadas ao } \\
\text { agronegócio. }\end{array}$ & $\begin{array}{l}\text { a) Dias de Campo, cursos, palestras, contatos } \\
\text { diretos dos técnicos e extensionistas com } \\
\text { agricultores; } \\
\text { b) Dias de Campo, palestras, cursos, feiras } \\
\text { agropecuárias, eventos técnicos, publicações } \\
\text { Embrapa; } \\
\text { c) Editais. }\end{array}$ \\
\hline \multirow{2}{*}{ 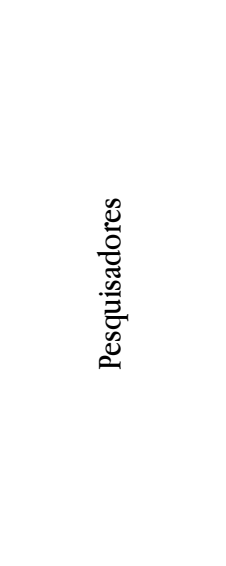 } & $\begin{array}{l}\text { a) Público externo } \\
\text { acadêmico; } \\
\text { b) Público interno } \\
\text { demais pesquisadores; } \\
\text { c) Chefia de P\&D e } \\
\text { demais chefias. }\end{array}$ & $\begin{array}{l}\text { a) Participação em eventos científicos internos e } \\
\text { externos à Embrapa, produção acadêmica; } \\
\text { b) E-mails, reuniões específicas, reuniões } \\
\text { quinzenais de pesquisa, seminários internos, } \\
\text { Reunião Anual de Pesquisa; } \\
\text { c) Reuniões de pesquisa, e-mails, relatórios, } \\
\text { Reunião Anual de Pesquisa. }\end{array}$ \\
\hline & $\begin{array}{l}\text { Público interno } \\
\text { profissionais de } \\
\text { comunicação; } \\
\text { Público interno } \\
\text { profissionais de } \\
\text { transferência de } \\
\text { tecnologia. }\end{array}$ & $\begin{array}{l}\text { E-mails, convites para participação em } \\
\text { reuniões específicas e nas reuniões de pesquisa } \\
\text { quinzenais, Reunião Anual de Pesquisa. }\end{array}$ \\
\hline
\end{tabular}

Fonte: Elaboração própria 
Na Fase 3, 73\% da amostra dos pesquisadores científicos responderam que conheciam o protocolo para o envio de informações entre a área de pesquisa e a área de comunicação - ou seja, o sistema denominado Agenda de Eventos. Contudo, apenas um terço deles (11 respondentes) disse que esse conhecimento era perfeito, e indicaram que tomaram conhecimento dele de nove formas diferentes, incluindo e-mails e "divulgação interna" promovidos pela equipe do NCO, artigos de divulgação publicados no Informativo Agrobiologia Acontece, e-mail do chefe do setor, e "pelo uso". Outros 11 respondentes informaram não conhecer perfeitamente esse canal e indicaram por que, sendo divididos em quatro grupos: a) efetiva e somente têm dúvidas sobre o protocolo, desconhecendo-lhe a existência formal, ou não sabendo se a Agenda de Eventos é o protocolo mencionado, ou não sabendo preencher o formulário do instrumento por ser atividade não muito frequente ou apenas periférica ao dia a dia do pesquisador, ou revelando-se inseguro sobre eventuais modificações recentes no protocolo; b) não têm mais do que uma noção a respeito do instrumento, por isso preferindo "atalhos" na comunicação com o NCO, tais como o envio direto das informações "as mais completas possíveis"; c) têm dúvidas a respeito de outro processo ou de outro assunto qualquer, tais como desconhecimento "do processo como um todo"; e d) críticos do modus operandi do protocolo, por exemplo defendendo o contato mais informal NCO-pesquisadores, entendendo o protocolo como "meio burocrático para uma empresa pequena" dado o "pequeno espaço físico que separa o NCO da área de pesquisa", menos "efetivo" do que o contato pessoal.

Quando perguntados se buscavam o apoio da área de comunicação quando o projeto requer ações e atividades, ou quando seus resultados estão prontos para divulgação, 27 (79\% da amostra) responderam positivamente e 06 (21\% da amostra) responderam negativamente. Dentre esses últimos, 04 (67\% dessa subamostra) não explicaram por que prescindem da área de comunicação, e 02 (33\% dessa subamostra) o fizeram: devido à admissão recente (implicando que ainda não surgiu a necessidade) e a questões práticas (por exemplo, imprimir banners "por conta própria, por ser rápido"). Já 11 dos 27 que responderam positivamente (41\% dessa subamostra) informaram conhecer e seguir o protocolo, 10 (37\% dessa subamostra) disseram que não o seguem por não o conhecerem, e 06 (22\% dessa subamostra) 
confessaram não seguirem o protocolo embora o conheçam. Para esses últimos, os motivos alegados foram de seis ordens: desorganização pessoal; julgamento pessoal de que o instrumento é "extenso", "burocrático", possuindo campos de preenchimento que "não têm muita relação com o tipo de evento"; distância física (existente entre a área de comunicação e a área de pesquisa); falta de tempo; maior praticidade e percepção de maior eficácia em procurar pessoalmente o apoio do NCO do que em utilizar o instrumento; e conhecimento insuficiente do instrumento.

Quando questionados se sabiam para quais tipos de público o NCO repassa informações sobre os resultados e as ações dos projetos, 07 respondentes ( $21 \%$ da amostra) responderam negativamente e 02 não responderam. Esses últimos ainda indicaram "parcialmente" em seguida, trazendo à tona um conhecimento superficial ou incipiente do processo. Dentre os 24 restantes ( $73 \%$ da amostra), os tipos de público informados foram o externo (agricultores, pesquisadores) e o interno (funcionários, bolsistas). Ao serem convidados a dizer se conheciam e como identificavam as formas como o NCO repassa as informações sobre os projetos para os diversos tipos de público, 12 respondentes (36\% da amostra) e 19 (58\% da amostra) responderam respectivamente de forma negativa e positiva, um pesquisador não respondeu e o outro respondeu reticentemente ("Alguns, na realidade não sei se conheço todos..."). Dentre aqueles que disseram não conhecer essas formas, metade as listou, o que leva a crer que a resposta negativa tenha a ver com sentirem-se inseguros quanto a realmente dominarem esse conhecimento. Houve a identificação de 17 públicos-alvo da Embrapa e de uma ampla variedade de formas, com acertos nessas identificações - muito embora se tenha observado alguma confusão ao relacionar a forma ao público respectivo.

Ao responderem sobre a frequência com que tomam conhecimento das ações adotadas pelo NCO para divulgar os resultados das pesquisas aos diversos públicos, e sobre sua opinião a respeito, $64 \%$ da amostra indicaram ter informações inadequadas a respeito dessas ações. Dentre os três que disseram nunca tomar conhecimento, um creditou ao fato de ser recém-admitido na empresa. Dentre os que disseram raramente tomar conhecimento das ações de divulgação, apenas nove emitiram opinião a respeito dessas ações: três se limitaram a elogios não só às ações em si como à equipe do NCO, e os seis outros aproveitaram para lançar 
críticas diversas a essas ações. Quando perguntados se haviam buscado algum apoio da área de comunicação da Embrapa Agrobiologia nos últimos três anos, 04 pesquisadores responderam negativamente ( $12 \%$ da amostra), 03 não responderam ( $9 \%$ da amostra) e os 26 restantes (79\% da amostra) responderam positivamente. Dentre esses últimos, os tipos de apoio buscados incluíram, por exemplo, apoio para palestras e para workshops, realização de treinamento, gravação de vídeos e divulgação na mídia, além da (inusitada, por não estar diretamente relacionada à área de comunicação) ajuda para a realização de coffee break.

Finalmente, 22 pesquisadores - ou seja, dois terços da amostra - deram sugestões para aprimorar o fluxo de informações entre sua área e o NCO, respostas que se encaixaram em quatro categorias: 1) Integração NCO-pesquisadores: o maior número de respostas remeteu à sensação dos respondentes de que é fraca a interação entre o NCO e a área de pesquisa; 2) Contato pessoal: ênfase no corpo a corpo, em detrimento ao contato protocolar, para a troca de informações entre as duas áreas, com ênfase na necessidade de os pesquisadores serem a parte procurada nesses encontros; 3) Desconhecimento das atividades do NCO: o terceiro maior número de sugestões remeteu ao desconhecimento das ações de divulgação, com a percepção de falta de agilidade e de proatividade do NCO; e 4) Rejeição ao atual procedimento para a interação: os pesquisadores mostraram-se desconfortáveis com a atual forma de interface com o NCO.

\section{DISCUSSÃO DOS RESULTADOS DO LEVANTAMENTO DE DADOS}

Se apenas 34\% dos pesquisadores conhecem perfeitamente o sistema Agenda de Eventos, essa divulgação aparentemente não tem sido suficiente em termos quantitativos e/ou qualitativos. Essa constatação é deveras preocupante se considerar-se que "A comunicação é como uma orquestra sem maestro, na qual todos os músicos são parte do show e fazem a sua própria música a partir de códigos comuns que orientam seus comportamentos" (BORELLI, 2005, p. 78). Isso se reforça com a verificação de que, no fluxo de informações entre a área de comunicação e o grupo de pesquisa, misturam-se formas claramente informais (via "E-mail do 
chefe do setor"), idiossincráticas ("pelo uso"), teoricamente inaceitáveis ("buscando informações diretamente no setor de comunicação" indica que o pesquisador é que tem que procurar se informar, aparentemente indicando ineficiência do NCO) e até mesmo incomuns ("experiência própria ao organizar eventos"). Nas respostas dos pesquisadores que informaram não conhecer perfeitamente esse canal e que explicaram por que, chamou a atenção haver pesquisadores que desconhecem que o protocolo existe, assim como também há aqueles que não lhe associam o nome Agenda de Eventos. Essa disassociação indicaria que os pesquisadores ou não têm noção alguma ou têm noção incompleta de a que se presta a Agenda de Eventos. Os prejuízos, nesse caso, podem ser inúmeros, já que comunicação é uma ponte de sentidos entre as pessoas, de tal forma que elas podem compartilhar aquilo que sentem e sabem, e cuja utilização pode garantir que uma pessoa cruze, com segurança, o rio de mal-entendidos que muitas vezes a separa das demais (KUNSCH, 2003).

Houve pesquisadores que informaram terem dúvidas sobre o preenchimento do formulário de solicitação por não saber lidar com os campos existentes, sugerindo que, quando da implantação do sistema da Agenda de Eventos, o trabalho de divulgação interna não foi suficiente para dirimir as dúvidas sobre o seu funcionamento. Por outro lado, houve pesquisador que não encara esse desconhecimento ("me parece que há um formulário específico") como um problema, tão somente "administrando" a situação à sua moda, definindo atalhos na sua comunicação com o NCO: ele prefere interagir com o NCO por meio de um canal alternativo, repassando, a esse último, as informações "as mais completas possíveis". Também ficou claro que reina confusão sobre o que é efetivamente o protocolo, havendo quem não conseguisse fazer-lhe a associação ao sistema da Agenda de Eventos. Isso parece confirmar que a capacidade de entendimento das mensagens por parte desses receptores da comunicação precisa ser mais bem compreendida na Embrapa, apesar de a divulgação ter sido realizada em diversos canais, como murais e outros veículos de informação. Não por acaso, Larkin $(2005$, p. 7$)$ diz que "A maior parte das mensagens as pessoas não querem ouvir", enquanto Cabral (2004) informa que talvez um dos maiores problemas da comunicação humana na vida organizacional seja a pretensão de que é fácil comunicar corretamente. Dentre esses 
não familiarizados, houve quem não se furtasse a se posicionar claramente contrário ao uso do protocolo - "o contato pessoal é mais efetivo". Um respondente que relatou dúvidas a respeito sobre o processo nessa e em diversas outras respostas do questionário se justificou com a frase "fui admitido recentemente na empresa". Esse fenômeno pode ser justificado de duas formas: a) pelo lado frágil da natureza da comunicação humana, conforme Cabral (2004, p. 69): "[...] por sua complexidade, sutilezas e singularidades, sempre pode provocar, ao contrário do que se propõe, incompreensão, mal-entendidos e/ou discordâncias entre seus interlocutores"; b) por uma falha na divulgação dos processos de trabalho na Unidade, já que recenticidade no pertencimento ao quadro de pesquisadores não deveria ser suficiente para implicar desconhecimento dos processos de trabalho.

Houve respostas relativas às dúvidas quanto ao protocolo que ultrapassavam as fronteiras desse ("Qual o tempo para receber o material de apoio, qual o custo, isso é arcado pelo projeto?"), assim como houve respostas que indicaram que o desconhecimento dos pesquisadores pode ultrapassar - em muito - apenas o protocolo em si ("Qual o tempo para receber o material de apoio, qual o custo, se isso é arcado pelo projeto"). Esse desconhecimento pode remeter a questões estruturais sobre procedimentos internos que transcendem as atividades do NCO e que podem ser vitais para a própria existência da Unidade.

As respostas que continham críticas sobre o modus operandi do protocolo indicaram que a visão dos pesquisadores quanto a esse instrumento é de burocracia. Para eles, em que pese a empresa ter perto de 150 colaboradores e estrutura e funcionamento consideravelmente complexos, ela seria pequena o suficiente para que os contatos fossem no corpo a corpo, que seriam mais eficientes do que aquele inserido em um processo formal. Essa necessidade de contato humano, como se o usuário do sistema sentisse que esse pode ser facilmente substituído por um simples tête à tête, deveria ser motivo de questionamento dentro da Unidade, compondo um mapeamento dos reais motivos da preferência pela adoção desses atalhos ao protocolo formal. De fato, deveria chamar a atenção do NCO que, dentre as respostas dos pesquisadores que confessaram não seguirem o protocolo embora 0 conheçam, tenha sido justificado que tal se dá por seu julgamento pessoal de que o instrumento é "extenso", "burocrático", possuindo campos de preenchimento que 
"não têm muita relação com o tipo de evento". Na verdade, esse distanciamento do recurso tecnológico, a favor do encontro pessoal, pode ter causas mais profundas do que apenas essas críticas registradas na pesquisa.

Esse raciocínio é complementado pelo fato de $64 \%$ da amostra terem indicado que recebem, com frequência aquém da ideal, informações das ações adotadas pela área de comunicação da Embrapa Agrobiologia para divulgar os resultados das pesquisas aos diversos públicos. Foram verificados dois tipos de crítica: a) aquela que não julga a eficácia das iniciativas de comunicação do NCO, mas sim sua seleção sobre o que divulgar e sobre quando divulgar; e b) aquela referente à forma como a divulgação é feita, mirando sua eficácia, que estaria aquém do desejável. Por outro lado, houve pesquisadores que elogiaram o trabalho do NCO, considerando-o importante e reconhecendo a competência dos profissionais da área. Essa mistura de posições reforça a percepção de que é muito importante que o NCO divulgue com muito mais afinco qual é o real papel da comunicação na Unidade, de modo que o grupo de pesquisa não crie expectativas distorcidas sobre o trabalho. Isso evitaria, por exemplo, uma certa confusão que a pesquisa mostrou sobre as formas como esse apoio se dá, já que houve respondente que aí incluiu serviços de apoio para coffee break.

Finalmente, quando convidados a dar sugestões para aprimorar o fluxo de informações entre o NCO e a área de pesquisa, a análise das condensações das respostas obtidas mostrou que o ponto de vista da área de pesquisa a respeito segue aproximadamente a seguinte lógica: 1) Os pesquisadores não têm tempo ("Pesquisadores [...] sempre estão com as mesas cheias"), nem lhes foi desenvolvida cultura ("Me parece que os pesquisadores devem ter maior iniciativa para procurar o setor de comunicação"), para buscar o apoio da área de comunicação para a divulgação dos resultados das pesquisas, e o canal da Intranet não é amigável com o usuário ("Provavelmente está muito fácil, mas eu gostaria de saber onde está esse protocolo para o envio de informações"); 2) Com isso, esse contato fica prejudicado, implicando, por sua vez, falta de clareza quanto à função, aos recursos e ao apoio disponibilizados pela área de comunicação, cujo plano de trabalho é desconhecido pelos pesquisadores ("É de extrema importância que fique claro, para todos os pesquisadores e demais funcionários, a função do setor [de comunicação] tanto no 
que se refere ao público interno quanto externo"); 3) A área de comunicação, por sua vez, é formalmente pouco envolvida de modo apriorístico com as atividades da área de pesquisa científica ("A área de comunicação precisa participar da elaboração das propostas de pesquisa"); 4) Esses desencontros levam os pesquisadores a entenderem que o modus operandi da área de comunicação é insuficiente ("Ela não se integra com as áreas de pesquisa e de transferência de tecnologia"), protocolar e burocrático; 5) Essa falta total de alinhamento induz a que se pense que a solução possa ser o contato pessoal, ao invés do impessoal, até porque já houve experiência nesse sentido, que foi avaliada positivamente ("Estagiários eram orientados por profissionais da área de comunicação e faziam contato direto ou por telefone com os pesquisadores da Unidade a cada semana”); e 6) Ao final, essa situação leva os pesquisadores a priorizarem contatos informais com os profissionais do NCO, atitude que retroalimenta o distanciamento deles do processo formalizado, assim como as distorções sentidas no desempenho do NCO, perpetuando-as.

\section{CONCLUSÃO, CONTRIBUIÇÃO, LIMITAÇÕES E INDICAÇÕES PARA FUTURAS PESQUISAS}

Dois pontos principais ficaram muito claros, ao final dessa pesquisa: a) metade dos pesquisadores reunidos na amostra desconhece as formas como o NCO repassa as informações sobre as ações e os resultados dos projetos para os diversos tipos de público; b) de uma forma geral, aos pesquisadores falta uma conscientização sobre o que significa a obediência a um protocolo processual. Têmse, portanto, duas situações dentro da Embrapa Agrobiologia: 1) aquela que se pode supor seja vivida pelo NCO, cujos profissionais seriam desafiados diuturnamente no desenvolvimento de suas atividades de rotina devido a esse desalinhamento entre as regras de comunicação estabelecidas e seus conhecimentos e cumprimento por parte dos pesquisadores científicos; 2) aquela que remete à posição dos pesquisadores, que, em um primeiro momento, pode indicar sua preferência por subverter essa ordem, conforme entendem que os trâmites comunicacionais são "burocráticos".

Contudo, a conclusão de que esse desencontro estaria evidenciando tão somente um urgente esforço de catequização dos pesquisadores no sentido de 
passarem a cumprir o protocolo formal de interação do NCO, pode, na verdade, revelar-se apressada e parcial. É fato que boa parte dos pesquisadores indicou ter dificuldade para compreender o sistema de protocolo da Agenda de Eventos como o único protocolo existente, no momento da pesquisa, para solicitação de apoios (agendamento de sala, solicitação de material como folders e banners, apoio em eventos). Independente de esse desencontro estar sendo alimentado pelo aparente mau posicionamento do sistema da Agenda na Intranet da Unidade (por meio de um ícone que supostamente lhe garantiria visibilidade, mas cujo efeito, a julgar pelos resultados dessa pesquisa - dúvidas, desconhecimento - ficou aquém do desejado), o que ali deveria ser investigado, prioritariamente, é se mesmo um aumento dessa visibilidade eliminaria o referido desencontro. Isso porque é natural que surja o seguinte questionamento: até que ponto os pesquisadores da Embrapa, com sua elevada formação científica e seu engajamento diuturno com pesquisas de ponta e de alta relevância para a agropecuária do País, de fato entenderiam ser relevante serem catequizados a dedicar parte do seu tempo a cumprirem tarefas distintas daquelas atinentes ao core do seu trabalho? Afinal, nas palavras de um deles, as mesas dos pesquisadores "estão sempre cheias". Ademais, além de não se poder esquecer que o contato face a face é considerado por alguns autores o mais rico no âmbito empresarial (PIMENTA, 2002), as relações de poder podem existir nos processos comunicacionais (FARIA; MENEGHETTI, 2001), sobretudo em uma organização onde o foco é a pesquisa científica e onde o quadro interno é predominantemente composto de pesquisadores.

Os resultados dessa pesquisa indicam que a melhoria na comunicação interna da Embrapa Agrobiologia poderia advir de algumas providências, tais como a formalização das maneiras que os pesquisadores indicaram como sendo de sua preferência para a interação com o NCO. Essas maneiras poderiam incluir os encontros pessoais, nos quais pesquisadores passam as informações sobre seus projetos e solicitam os apoios necessários. Uma possibilidade seria, por exemplo, resgatar a ação de estagiários que procuravam o núcleo de pesquisa para coletarem não só as informações oriundas dos resultados das pesquisas; também poderia ser providenciada uma maior interação dos profissionais do NCO com as atividades de pesquisa, já que houve relatos reclamando que a área de comunicação é formalmente pouco envolvida de modo apriorístico com as atividades da área de pesquisa científica. 
A contribuição acadêmica dessa pesquisa reside no fato de haver indicado que, para que a comunicação interna corporativa se dê na fluidez necessária à garantia do repasse das informações aos stakebolders externos, é necessário mais do que apenas o desenho de um processo teoricamente correto. As características intrínsecas dos agentes envolvidos - no caso examinado aqui da Embrapa Agrobiologia, os pesquisadores científicos - devem ser levadas em conta nesse desenho, de forma que não subsistam resistências pessoais à sua transformação em ações concretas.

Dentre as limitações dessa pesquisa, podem-se listar três: 1) a característica de comunicação intencional, linear e assimétrica do modelo de Lasswell (1935) limita a riqueza dos resultados obtidos com sua utilização; 2) os vieses clássicos da pesquisa "de quintal" indicados por Creswell (2010), já que a pesquisadora é funcionária da empresa escolhida como objeto de estudo; e 3) a provável intimidação ou constrangimento sentidos por alguns dos cientistas-pesquisadores devido à proximidade do trabalho com a pesquisadora, o que os teria levado a calibrar suas respostas conforme se sentiram mais ou menos confortáveis quanto às perguntas. Futuros estudos poderão investigar a visão dos profissionais lotados na área de comunicação da Embrapa Agrobiologia quanto à interface com os pesquisadores científicos, assim como realizar o mesmo mapeamento em outras Unidades da Embrapa.

\section{REFERÊNCIAS}

AKTOUF, O. A administração entre a tradição e a renovação. São Paulo: Atlas, 1996.

ARAÚJO, V. M. R. H. de; FREIRE, I. M. A rede internet como canal de comunicação na perspectiva da ciência da informação. Transinformação, v. 8, n. 2, 1996.

BARDIN, L. Análise de conteúdo. São Paulo: Edições 70, 1977.

BUENO, W. Comunicação empresarial no Brasil: uma leitura crítica. São Paulo: All Print, 2005.

BORELLI, V. É impossível não comunicar: reflexões sobre os fundamentos de uma 
nova comunicação. Revista Diálogos Possíveis, v. 4, n. 2, ago./dez.2005. Disponível em: $\quad<$ http://www.faculdadesocial.edu.br/dialogospossiveis/artigos/7/06.pdf $>$. Acesso em:5 nov.2013.

CABRAL, V. Um ensaio sobre a comunicação interna pós-industrial em sua dicotomia discurso e prática. ORGANICOM- Revista Brasileira de Comunicação Organizacional e Relações Públicas, v. 1, n. 1, p. 57-71, ago. 2004.

CARDOSO, O. Comunicação empresarial versus comunicação organizacional: novos desafios teóricos. RAP, v. 40, n. 6, p. 1123-1144, nov./dez. 2006

CLEGG, S. Poder, linguagem e ação nas organizações. In: CHANLAT, Jean- François et al. O indivíduo na organização: dimensões esquecidas. São Paulo: Atlas, 2007. p. 47-66.

CLEMEN, P. Como implantar uma área de comunicação interna. São Paulo: Mauad, 2005.

COLAUTO, R.; BEUREN, I.; MECCA, M.; PINHEIRO, L. Identificação dos canais de comunicação mercadológica utilizados como mecanismos para delineamento do planejamento estratégico. ConTexto, v. 6, n. 9, 2006.

CRESWELL, J. Projeto de pesquisa: métodos qualitativo, quantitativo e misto. Porto Alegre: Bookman, 2010.

CURVELLO, J. A comunicação na nova empresa. Boletim de Informação ao Pessoal (BIPEL) do Banco do Brasil, São Paulo, n. 1000. 1997. Disponível em: < http:// www.acaocomunicativa.pro.br/jo01005.htm > . Acesso em: 07 jul. 2014.

DUARTE, J.; RIBEIRO, R. Comunicação em ciência e tecnologia: estudos da Embrapa. Brasília, DF: Embrapa Informação Tecnológica, 2006.

EMBRAPA. Política de comunicação da Embrapa. 2. ed. rev. e ampl. Embrapa: Brasília, DF, 2002.

EMBRAPA. Secretaria de Gestão Estratégica. V Plano Diretor da Embrapa: 20082011-2023. Brasília, DF: Embrapa Informação Tecnológica, 2008. 44 p.

ETKIN, R. Capital socialyvalores en la organizacion sustentable: eldeberser, poder 
hacer y la voluntad creativa. Buenos Aires: Granica, 2007. Disponível em: < http:// books.google.com/books?id = qeij4773xlAC\&pg $=$ PA196\&lpg $=$ PA196\&dq $=\% 22 j$ orge + etkin $\% 22+$ dualidad $\&$ source $=$ bl\&ots $=$ PWqft $21 \mathrm{CXv} \&$ sig $=$ N3GHDEe-8RT rB75B2XS4IPySeik\&hl=en\&ei $=$ fHHrTfjbAoHHgAeUovnYCQ\&sa $=$ X\&oi = book result $\& \mathrm{ct}=$ result $\&$ resnum $=1 \& \mathrm{ved}=0 \mathrm{CBUQ6AEwAA} \# \mathrm{v}=$ onepage $\& \mathrm{q} \& \mathrm{f}=$ false $>$. Acesso em: 13 jul. 2014.

FARIA, J. H.; MENEGHETTI, F. K. Discursos organizacionais. In: ENCONTRO NACIONAL DA ASSOCIAÇÃO NACIONAL DOS PROGRAMAS DE PÓS-GRADUAÇÃO E PESQUISA EM ADMINISTRAÇÃO, 26., 2001, Campinas. Anais... Campinas, SP: ENAnpad, 2001.

FELISBINI, P. Comunicação e gestão de mudanças: estudo de caso em uma indústria química. ORGANICOM - Revista Brasileira de Comunicação Organizacional e Relações Públicas, v. 1, ago. 2004.

GALINDO, D. A comunicação integrada de marketing e o seu caráter multidisciplinar. In: KUNSCH, M. M. K. (Org.) Comunicação organizacional: histórico, fundamentos e procesos. São Paulo: Saraiva, 2009. vol. I.

GOMES, P.; SANTOS, J.; RODRIGUES, V. Comunicação Empresarial em um Processo de Fusão de Empresas: uma análise da União Braskem. Revista Gestão \& Tecnologia, v. 12, n. 2, p. 192-216, jul./nov. 2012.

GONÇALVES, C.; MEIRELLES, A. Projetos e relatórios de pesquisa em administração. São Paulo: Atlas, 2004.

HALL, R. Organizações: estrutura e processos. 3. ed. Rio de Janeiro: Prentice- Hall do Brasil, 1984.

ILUFI, O. Teoria da Comunicação e teoria semiótica: sua incorporação ao processo de formação universitária do contador no Chile. In: CONFERÊNCIA ACADÊMICA PERMANENTE DE PESQUISA EM CONTABILIDADE, 11., 2000. Anais... Talca, Chile, 2000.

KOTLER, P. Marketing. 3. ed. São Paulo: Atlas, 1998.

KUNSCH, M. Planejamento de relações públicas na comunicação integrada. 4. ed..rev. atual.e.ampl. São Paulo: Summus, 2003. 
LARKIN, T. Face a face, a melhor forma de comunicar. Entrevista concedida a Nara Damante. Revista Comunicação Empresarial, v. 15, n. 57, p. 4-7, 2005.

LASSWELL, H. World politics and personal insecurity. McGrawHill: New York, 1935.

LUPETTI, M. Gestão estratégica da comunicação mercadológica. São Paulo: Thomson Learning, 2007.

MATOS, G. Comunicação empresarial sem complicação: como facilitar a comunicação na empresa, pela via da cultura e do diálogo. 2. ed. rev. e ampl. Barueri: Manole, 2009.

MELO, V. A comunicação interna e sua importância nas organizações. 2009. Disponível em: < http://www.fag.edu.br > . Acesso em: 10 out. 2010.

MILLER S.; HICKSON, D.; WILSON, D. A tomada de decisão nas organizações. In: CALDAS, M.; FACHIN, R.; FISHER, T. (Org.). Handbook de estudos organizacionais: ação e análise organizacionais. São Paulo: Atlas, 2004. Vol. 3, p. 282-310.

NASCIMENTO, V. A comunicação interna como estratégia de visibilidade para a educação profissional no interior. 2010. Disponível em: < http://www.bocc. ubi.pt/pag/nascimento-valeria-a-comunicacao-interna-como-estrategia.pdf $>$. Acesso em: 10 jul. 2011.

NASSAR, P. (Org). Comunicação interna: a força das empresas. São Paulo: Aberje, 2006. Vol. 3.

NOGUEIRA, T.; TOMEI, P. Comunicação e construção do significado em mudanças organizacionais planejadas. R. eletr. estrat. neg., v. 6, n. 2, p. 177-216, mai./ago. 2013.

PEREIRA, A.; MIRANDA, A. Comunicação: ferramenta de marketing interno para novos modelos de gestão. In: ENCONTRO NACIONAL DE ENGENHARIA DE PRODUÇÃO, 27., 2007, Foz do Iguaçu. Anais... Foz do Iguaçu: [s.n.], 2007.

PIMENTA, M. Comunicação empresarial. 3. ed. Campinas: Alínea, 2002.

ROMAN, A. Organizações: um universo de discursos bem-ditos, mal-ditos e não- 
ditos. In: KUNSCH, M. M. K. (Org.). Comunicação organizacional: linguagem, gestão e perspectivas. São Paulo: Saraiva, 2009. vol. 2.

ROBBINS, S. P.; JUDGE, T. A.; SOBRAL, F. Comportamento organizacional: teoria e prática no contexto brasileiro. 14. ed. São Paulo: Pearson Prentice Hall, 2011.

SCROFERNEKER, C. Perspectivas teóricas da comunicação organizacional. Disponivel em: <http://www.esurp.edu.br/Nergetti_PerspectivasTeoricasComOrg. pdf > . Acesso em: 13 jul. 2014.

SILVA, A.; SILVA, C. A comunicação corporativa como estratégia de gestão. 2010. Disponivel em: < http://www.aedb.br/seget/artigos10/513_artigo.Anna.2010.pdf. $>$. Acesso em: 25 jan. 2012.

SOARES, V. Fluxo de informação x relações de poder: jogo empatado. 2004. Disponível em: $\quad<$ http://www.bocc.ubi.pt/_listas/tematica.php?codtema $=5>$. Acesso em: 05 jan. 2012.

SOUZA, J. Elementos de teoria e pesquisa da comunicação e dos media. $2^{\mathrm{a}}$ ed. rev. e ampl. Porto: [s.n.], 2006.

SOUZA, R.; AÑEZ, M. O uso da política cognitiva na comunicação organizacional. Organizações em Contexto, v. 8, n. 15, jan.jun. 2012.

TERCIOTTI, S. O Poder, a comunicação e o diálogo no ambiente organizacional. ORGANICOM - Revista Brasileira de Comunicação Organizacional e Relações Públicas, v. 5, n. 9, 2008.

TIBÉRIO, S. Modelos de comunicação: comunicar e conhecer. 2010. Disponível em: < http://comunicareconhecer.blogspot.com.br> Acesso em: 20 jan. 2012.

VERGARA, S. Métodos de pesquisa em administração. 4. ed. São Paulo: Atlas, 2010.

YIN, R. Estudo de caso: planejamento e métodos. 3. ed. Porto Alegre: Bookman, 2005. 
504 Uma palavra vale mais do que um protocolo? (in)formalidade na comunicação interna...

Recebido em: 19 de abril de 2014

Aceito em: 20 de agosto de 2014 